professionals to recognise the dying person and responding to their needs was inconsistent.

\section{P-107 GOOD ENOUGH TO EAT: ENCOURAGING NUTRITIONAL INTAKE AND REAWAKENING APPETITE ON THE IN- PATIENT UNIT}

Nicola Hanmer, Tracy Parkinson. St Catherine's Hospice, Preston, UK

10.1136/bmjspcare-2018-hospiceabs. 132

Introduction A balanced diet and adequate fluid intake is important, especially for those with a life-shortening condition. In 2016 St Catherine's Hospice formed a Nutrition Focus Group, tasked with ensuring person-centred nutritional care for patients.

Aims To develop initiatives to increase food and fluid intake for patients. To re-awaken appetite in patients whose conditions have affected their desire to eat and drink. To widen choices. To modernise the presentation of meals, snacks and refreshments to better reflect the quality of dishes being served. To ensure meals, snacks and refreshments are served in an accessible way. To improve access to nutritious food for families 24/7. To promote the social element of sharing food and drink with loved ones.

Method We have made various improvements around three themes:

1. Food/drink/snacks. Extended choice on refreshments trolley to include filter coffee, fruit teas, fruit platters and smoothies. Continue to offer personalised choices alongside daily set menu. Continue to offer suggestions to those struggling to make food choices. Improved the variation in the pureed/soft foods menu

2. Accessibility. Invested in specialist equipment. Opened coffee bar in gift shop selling drinks, snacks and home-cooked ready meals 24 hours a day

3. Socialisation/normalisation. Invested in new trays and cutlery. Introduced linen napkins to improve the experience of having a meal and develop its sense of occasion. Refurbished the conservatory into a comfortable space where patients and loved ones can enjoy refreshments together. Invested in new moulds to improve the presentation of pureed/soft foods.

Evaluation Feedback is positive:

'My appetite has been dire for last 18 months and since being here has vastly improved', in-patient.

'Mum sometimes is not aware of what she wants so ideas are good', daughter of an in-patient.

\section{P-108 HYDRATION AT THE END OF LIFE: COLLABORATION AND EDUCATION TO EMBED CHANGE IN PRACTICE}

\footnotetext{
${ }^{1}$ Andrew Fletcher, ${ }^{2}$ Kathryn Woods, ${ }^{2}$ Louise Dowthwaite, ${ }^{1}$ Helen Jones, ${ }^{2}$ Stacey Batty, ${ }^{3}$ Claire Capewell. 'St Catherine's Hospice, Preston, UK; ${ }^{2}$ Lancashire Care Foundation Trust, Preston, UK; ${ }^{3}$ Lancashire Teaching Hospital NHS Trust, Preston, UK
}

\subsection{6/bmjspcare-2018-hospiceabs.133}

Background 'One chance to get it right' (Leadership Alliance for the Care of Dying People, 2014) and NICE guidance (National Institute for Health and Care Excellence, 2015) highlight the need to ensure appropriate means of providing hydration at end of life is available across care settings, including the availability of Clinically Assisted Hydration. Across our locality, the processes were not in place to achieve this and there was concern about understanding of the factors informing decision making.

Aims Develop procedure for the Administration of Subcutaneous Fluids in Adults at End of Life in the Community. Ensure robust mechanisms in place for monitoring management of hydration at end of life. Develop patient/carer information. Provide multi-professional education and training.

Methods Collaborative task and finish group established. Available literature reviewed to develop a patient/carer information leaflet. Multi-professional education and training package developed to enhance understanding of assessment and decision making.

Results Procedure for the Administration of Subcutaneous Fluids in Adults at End of Life in the Community was developed and agreed by our local community NHS Trust, hospice and clinical commissioning groups. Associated information contains a flowchart and other guidance. An audit proforma was developed to collect prospective data about the use and impact of subcutaneous fluids at end of life. A patient information leaflet was developed with agreement of partners. Multi-professional education and training was delivered to over 150 clinicians through attendance at GP training afternoons and hospice sessions (Macmillan grant funded).

Discussion A procedure has been agreed to ensure methods available to provide hydration support for patients at end of life, not limited by the place in which the person is being cared for. Feedback received from 89 attendees at the hospice education programme - score 1-6, 6 being excellent, 99\% of responders scored 5 or 6 ; $94 \%$ recommended the session. Qualitative feedback reflected the need for individualised assessments and staff feeling empowered to support patients.

\section{P-109 A MEAL TO DIE FOR}

Vera Mircescu. Mountbatten Hospice, Newport, UK

\subsection{6/bmjspcare-2018-hospiceabs.134}

Background Food is at the core of our existence and wellbeing. It provides familiarity and comfort, it brings families and friends together. In the context of palliative care, food choice can be seen as the sole opportunity for a patient to still make their own choices.

In our relentless pursuit to improve quality of life for our patients we identified the need to make food readily available to our patients throughout the day. Set meal times are not suited to the unpredictable nature of a hospice patient's daily schedule.

Aim To provide nutritious, tailor-made, enticing meals and drinks in the form of hotel room-service when our patients and their visiting families or friends want and need them. In addition to an á la carte menu we strive to meet any patient request for food, regardless of how difficult to source it may be.

Method Consultation meetings carried out with the medical teams. Á la carte menu created with nutritionist support. Food service trial sessions carried out involving patients, families and medical. Evaluation of food service trials. Patient survey carried out - feedback provided.

Results Improved patient nutrition as meal times were not missed. Increased patient satisfaction recorded as a result of 